\title{
Understanding the Prevalence and Geographic Heterogeneity of SARS-CoV-2 Infection: Findings of the First Serosurvey in Uttar Pradesh, India
}

\author{
Vasanthakumar Namasivayam ${ }^{1}$ (D ) Amita Jain ${ }^{3} \cdot$ Vikasendu Agrawal $^{4} \cdot$ Ravi Prakash $^{1} \cdot$ Bidyadhar Dehury $^{2}$. \\ Marissa Becker ${ }^{1} \cdot$ James Blanchard $^{1}$. Shajy Isac ${ }^{1,2} \cdot$ Amit Mohan Prasad $^{4}$
}

Received: 17 May 2021 / Accepted: 15 October 2021 / Published online: 26 October 2021

(C) The Author(s) 2021

\begin{abstract}
Population-based serological antibody test for SARS-CoV-2 infection helps in estimating the exposure in the community. We present the findings of the first district representative seroepidemiological survey conducted between 4 and 10 September 2020 among the population aged 5 years and above in the state of Uttar Pradesh, India. Multi-stage cluster sampling was used to select participants from 495 primary sampling units (villages in rural areas and wards in urban areas) across 11 selected districts to provide district-level seroprevalence disaggregated by place of residence (rural/urban), age (5-17 years/aged $18+$ ) and gender. A venous blood sample was collected to determine seroprevalence. Of 16,012 individuals enrolled in the study, 22.2\% [95\% CI 21.5-22.9] equating to about 10.4 million population in 11 districts were already exposed to SARS$\mathrm{CoV}-2$ infection by mid-September 2020 . The overall seroprevalence was significantly higher in urban areas $(30.6 \%, 95 \%$ CI 29.4-31.7) compared to rural areas (14.7\%, 95\% CI 13.9-15.6), and among aged $18+$ years (23.2\%, 95\% CI 22.4-24.0) compared to aged 5-17 years $(18.4 \%, 95 \%$ CI 17.0-19.9). No differences were observed by gender. Individuals exposed to a COVID confirmed case or residing in a COVID containment zone had higher seroprevalence $(34.5 \%$ and $26.0 \%$, respectively). There was also a wide variation (10.7-33.0\%) in seropositivity across 11 districts indicating that population exposed to COVID was not uniform at the time of the study. Since about $78 \%$ of the population (36.5 million) in these districts were still susceptible to infection, public health measures remain essential to reduce further spread.
\end{abstract}

Keywords COVID-19 $\cdot$ SARS-CoV-2 $\cdot$ Seroprevalence $\cdot$ Heterogeneity $\cdot$ Uttar Pradesh $\cdot$ India

\section{Introduction}

The World Health Organisation (WHO) declared severe acute respiratory syndrome coronavirus 2 (SARS-CoV-2), or the novel coronavirus, to be a public health emergency of

Joint First Author: Vasanthakumar Namasivayam and Amita Jain.

Vasanthakumar Namasivayam

drvasanth@ihat.in

1 Department of Community Health Sciences, Institute for Global Public Health, University of Manitoba, R070 Med Rehab Bldg, 771 McDermot Avenue, Winnipeg, MB R3E 0T6, Canada

2 India Health Action Trust, New Delhi/Lucknow, India

3 King George's Medical University (KGMU), Lucknow, India

4 Government of Uttar Pradesh, Lucknow, India international concern in March of 2020 [1]. By the end of 2020, over 81 million people worldwide had been diagnosed with COVID-19, and 1.8 million had died [2]. Available evidence suggests that reported figures considerably understate the extent of the spread of the virus [3]. With over $80 \%$ of the total cases estimated to be asymptomatic, it has been widely acknowledged that laboratory-based surveillance systems have not been able to capture the total magnitude of the virus spread. As such, the prevalence rates of COVID-19 within the population remain largely underestimated [3, 4].

Serological antibody testing of the population becomes important as it can enable improved understanding and can help derive correct estimates of the true extent of the disease spread [5]. An antibody-based testing strategy has been recommended by the WHO for overcoming the limitation of selective testing of facility-based surveillance systems and to better estimate the prevalence of both asymptomatic and mildly symptomatic cases in the community [6]. Numerous 
countries heavily afflicted by the pandemic have conducted large-scale serosurveys using serologic antibody tests to help quantify the actual burden of COVID-19 [7]. Different methods (rapid tests, lateral flow immunoassays and ELISAbased tests) and strategies of testing (drive-through testing, school-based testing and volunteer screening) have been implemented. Positivity rates in population-based surveys have ranged from $5.0 \%$ in Spain to $5.3 \%$ in France $[8,9]$, while the prevalence levels ranged from $14.0 \%$ in New York, USA and Gangelt, Germany to $10.8 \%$ in Geneva, Switzerland and $0.5 \%$ in San Miguel County, USA [4, 10].

Similarly, in India, federal agencies, states and cities have conducted various independent studies to estimate seropositivity levels including the studies conducted by the Indian Council of Medical Research (ICMR), the apex health reaserch institute of India. With 28,000 adults from the 70 districts of the 21 states of India, the first serological study by ICMR revealed a pooled adjusted seropositivity rate of $0.73 \%$, indicating that nearly 6.4 million people had been exposed to COVID-19 by early May 2020 [11]. A subsequent survey by ICMR covering more than 29,000 individuals aged 10 years and above across the country, estimated seropositivity to be $6.6 \%$ by the end of September 2020 and $21.4 \%$ by mid-December $2020[12,13]$. This indicated that approximately 280 million people cumulatively had been infected by the virus by the end of 2020 in India. Higher prevalence was reported in urban slums (15.6\%) compared to urban non-slums (8.2\%) and rural geographies (4.4\%). Statelevel surveys in Punjab (May 2020) and Andhra Pradesh (June 2020) detected SARS-CoV-2 prevalence of $24.2 \%$ and $19.7 \%$, respectively $[14,15]$. Localised serosurveys found even higher rates of virus exposure. For example, investigations in the country's major urban locales revealed seropositivity to be as high as 51.3\% in Pune city, 22.9\% in Delhi and $23.2 \%$ in Ahmedabad city [16-18] by July 2020. In Mumbai, positivity rates were observed to be considerably higher among slum residents (54.1\%) compared to the non-slum urban population (16.1\%) during the same period [19].

In Uttar Pradesh (UP), the most populous state in India with an approximate population of 225 million [20], the number of confirmed cases of COVID-19 by the end of August 2020 stood at 230,414 [21, 22]. While some serosurveys had been conducted in different parts of the country, similar estimates from high-burden districts of UP were largely missed. The national-level serosurvey conducted by ICMR had covered certain districts in UP, yet district-level estimates could not be derived due to the survey design and relatively smaller district-level sample size. Given the expanse of the state and its centrality to the country's efforts to further contain the spread of COVID-19, understanding the heterogeneity in prevalence levels was required. We implemented a seroprevalence study to understand the epidemiological profile of disease burden by geography (rural/ urban and high/low prevalence districts), population subgroups (age and gender) as well as other high-risk categories (people with known comorbidities, including diabetes, hypertension, immunocompromised conditions and severe acute respiratory illnesses, among others). Findings of the study would have important programmatic relevance in informing the strategy to help mitigate the epidemic locally.

\section{Materials and Methods}

\subsection{Study Setting}

The Government of UP (GoUP), in collaboration with King George's Medical University (KGMU), Lucknow, and the Uttar Pradesh Technical Support Unit (UPTSU) of the University of Manitoba (UoM) and India Health Action Trust (IHAT), conducted its first district-level seroepidemiological study in 11 districts of UP to estimate the prevalence of infection among the population aged 5 years and above. These districts were identified by the state government based on the relatively high burden of cases reported from these geographies and were among those not covered in the national serosurvey conducted by ICMR. These 11 districts together contributed $20 \%$ of the total population in the state and $40 \%$ of the total COVID-positive cases at the time the survey was conducted.

\subsection{Sampling Design and Participants}

A multi-stage cluster sampling approach was used for this study implemented in rural and urban areas of 11 districts of the state between September 4th and 10th, 2020. The study estimated 1440 samples assuming a three per cent seropositivity rate for COVID-19 for each of the selected districts, with a precision rate of $1.5 \%, 95 \%$ Confidence Interval $(\mathrm{CI})$, design effect of 2.5 and an assumption of $10 \%$ non-response rate (including sample wastage). This amounted to an estimated 15,840 respondents, of which 8928 and 6912 were allocated to rural and urban geographies, respectively. Within each of the selected districts, simple random sampling was used to select 45 Primary Sampling Units (PSU), which constituted census villages in rural areas and wards in urban areas. Altogether, it resulted in 495 PSUs across 11 districts. The catalogue of villages and wards from the 2011 Census was used as the sampling frame. As per the 2011 Census, the rural:urban population proportion of Uttar Pradesh was 78:22 percent. For the 11 districts in which the seroprevalence survey was conducted, the proportion of rural:urban population was 55:45 percent. Accordingly, the number of PSUs within each district was assigned to reflect the respective district's rural-urban population composition. To ensure representativeness of the samples collected from each of the selected PSUs, we divided each PSU into 4 segments and selected an equal number of samples from each of the 4 segments. By selecting 
8 samples from each of the 4 segments within a PSU, we were able to collect 32 samples which would provide adequate samples to calculate the seroprevalence stratified by age and gender at the district level. Thus, the district-wise sample size was allocated as 32 samples across 45 PSUs to achieve 1440 samples per district. The first household within each segment was selected randomly and the remaining 7 households were sequentially selected thereafter. Of these 8 households, the initial 6 households were chosen for the selection of adult individuals ( 3 men and 3 women), while children aged 5-17 were selected from the remaining 2 households. Only one individual was randomly selected per household. A framework depicting the sample selection process is provided in Fig. 3 .

\subsection{Data Collection Process}

Following an informed written consent, selected participants answered a brief questionnaire that included their socio-demographic profile, history of symptoms compatible with COVID-19 (fever, sore throat, cough, breathlessness), mobility within and outside the community, contact with confirmed COVID-19 cases, history of comorbidities; and had a venous blood sample collected for subsequent laboratory analysis to detect antibodies against SARS-CoV-2.

A total of 110 study teams were constituted, with ten teams being formed in each district. Each study team composed of a Medical Officer (MO), Lab Technician (LT), Community Mobiliser and an interviewer. The UPTSU was involved in survey design, study tool development, data collection monitoring, protocol development, training of investigators as well as data analysis. A data entry module was also developed by UPTSU using Open Data Kits (ODK) to ensure real-time data collection and recording. KGMU was responsible for specimen processing and testing as well as result entry on a web-based portal.

After obtaining written consent, venous blood sample and behavioural data were collected by the health department of GoUP using a central camp approach, wherein selected participants as per study design were mobilized to the camp for interview and blood sample collection. The camp was situated at a central or convenient place within each PSU for easy accessibility. The LT was responsible for blood specimen collection whereas the interviewer collected behavioural information. All the interviews were conducted in a private space to maintain participants' confidentiality. The MO was in-charge of overseeing the entire data collection process and ensuring adherence to the study protocols. Data collection in a single PSU was completed in 1 day and the blood samples were transported to KGMU, in sealed and sterile packed containers, on the same day following a strict protocol.

\subsection{Serology Testing Procedures}

The SARS-CoV-2 serological tests were done using 'COVID KAVACH ELISA (enzyme-linked immunosorbent assay)' rapid diagnostic tests (RDTs) to detect the presence of IgG antibodies in the blood sample. RDT relies on a lateral flow assay that returns qualitative (positive or negative) results within minutes. The test does not provide quantitative results indicating the amount of antibodies in the specimen. The technology used for this serological testing was approved by ICMR and the manufacturer reported a test specificity of $97.90 \%$ and $92.37 \%$ sensitivity [23].

During data collection, if an individual was found to be displaying standard symptoms of COVID-19-persistent fever, dry cough, sore throat or breathlessness and/or they were found to be COVID-19 positive, they were still included in the main survey. Symptomatic individuals, and those testing COVID-19-positive on RDT, were provided with appropriate information on the nearest available facilities for COVID-19 testing and were also linked to available healthcare facilities to ensure immediate treatment. Adequate COVID-19 personal protective equipment (PPE) and training were provided by GoUP to the field team to ensure their safety.

\subsection{Statistical Analysis}

Descriptive analysis was done on the characteristics of the study participants, including place of residence, household size, age, gender, occupation, workplace characteristics, travel history for work or any other purpose, comorbidity status, smoking status, a history of a household or community member who tested positive for COVID-19 and history of contact with someone who had tested COVID-19 positive. Size of the household was categorized into three groups-households with $<5$ members, 5-6 members and $7+$ members based on the distribution of household size found in the study. Comorbidity status refers to self-reported hypertension or diabetes at the time of the survey. Percent distribution, mean, Standard Deviations (SD), and median were reported to describe the characteristics of the participants. The pooled data from the selected 11 districts were used to estimate the seroprevalence of antibodies against SARS-CoV-2 with 95\% CI at the aggregate level for overall as well as by age, gender and place of residence. Appropriate sampling weights were computed to generate weighted seroprevalence. Further, the weighted seroprevalence was adjusted for the test performance considering the estimated sensitivity $(92.37 \%)$ and specificity $(97.90 \%)$ of the assay [24] using the formula [25]: 
Adjusted seroprevalence $=\frac{\text { weighted seroprevalence }+ \text { specificity }-1}{\text { sensitivity }+ \text { specificity }-1}$.

Adjusted seroprevalence was also estimated for each of the 11 districts and as well as stratified by place of residence (rural, urban), age group (5-17 years, 18 years and above) and gender (male, female). The variation in the seroprevalence by PSUs was also analysed to assess the association of seroprevalence and population size. That is, we examined whether bigger PSUs (measured through relatively higher population size) had higher seroprevalence compared to the smaller PSUs. Further, PSUs were grouped into three categories based on the distribution of seroprevalence at the PSU level. Since the overall seroprevalence in the 11 districts was $22 \%$, we created the following three categories: (1) PSUs with zero seropositivity versus; (2) those having seropositivity up to the near average $(<20 \%)$; and (3) those PSUs with more than $20 \%$ seroprevalence. The analysis was carried out among 16,012 participants using STATA version 16.0 [26].

\subsection{Ethical Considerations}

The study received ethical approval from the Institutional Ethics Review Board (IERB) of KGMU, Lucknow (1062/ ethics/2020). Written informed consent was obtained from each adult participant before the interview. For participants aged 5-17 years, assent was obtained from them and written consent was also taken from the parents or the adult member who accompanied them at the study site. The study also allowed a maximum of an additional five samples from each PSU to accommodate volunteer participation. The anonymity of the respondents was maintained by labelling each participant with a unique identification code composed of the PSU number and the serial number of participants generated automatically in ODK.

\section{Results}

Of the total 16,012 participants, 7000 (47.0\%) were from urban and 9012 (53.0\%) were from rural areas. While 8253 $(51.2 \%)$ respondents were male, $7759(48.8 \%)$ were female. Participants aged 5-17 years comprised $21.3 \%$ of the total sample, while those aged 18-39 years, $40-59$ years and $60+$ years constituted $48.6 \%, 27.3 \%$ and $2.9 \%$ of the sample, respectively. Of the total respondents aged 18 and above, $23.7 \%$ were engaged in either business or service, $23.0 \%$ were employed in agriculture, $31.9 \%$ were homemakers and $12.3 \%$ were unemployed. Furthermore, $10.0 \%$ of adults were smokers, and $3.7 \%$ reported any comorbidity. History of contact with a person having a confirmed case of COVID19 was reported by $1.6 \%$ of participants (Table 1 ).

Table 2 depicts the seroprevalence rates across the different population groups. For the 11 districts combined, the weighted seroprevalence adjusted for test performance was $22.2 \%$ [95\% CI 21.5-22.9] with $30.6 \%$ seropositivity in urban areas [95\% CI 29.4-31.7], and $14.7 \%$ [95\% CI 13.9-15.6] in rural areas. The seropositivity was $18.4 \%$ [95\% CI 17.0-19.9] among younger participants aged 5-17 years, followed by $22.5 \%$ [95\% CI 21.4-23.5], 24.3\% [95\% CI 22.9-25.7] and 25.4\% [95\% CI 21.3-30.0] among participants aged $18-39$ years, $40-59$ years and $60+$ years, respectively. No major variations in seropositivity rates were noticed between males (22.2\% [95\% CI 21.2-23.2]) and females (22.2\% [95\% CI 21.2-23.2]), and among participants belonging to different household sizes-23.3\% [95\% CI 21.9-24.8] in household size < 5, 22.0\% [95\% CI 20.9-23.2] in household size of 5-6 and $21.5 \%$ [95\% CI 20.3-22.7] in household size of $7+$.

The seropositivity rates were relatively higher $(28.6 \%$ [95\% CI 26.6-30.6]) among people engaged in business, followed by professionals (25.4\% [95\% CI 22.0-29.1]), homemakers (24.3\% [95\% CI 22.9-25.8]), unemployed (23.7\% [95\% CI 21.4-26.1]) and those who engaged in agricultural work (18.1\% [95\% CI 16.6-19.7]). Seroprevalence was $26.0 \%$ [95\% CI 22.7-29.7] among those participants whose workplace came under a containment zone or were in a COVID-19 hotspot area compared to their counterparts (21.6\% [95\% CI 20.3-22.9]).

The prevalence rates were significantly higher among those who reported a family member being COVID19-positive in the 6 months preceding the date of the survey (40.6\%, 95\% CI 33.3-48.5) compared to those who had no such exposure (21.9\%, 95\% CI 21.2-22.7). The participants who reported having had contact with a confirmed case in the past 6 months also had significantly higher seroprevalence $(34.5 \%, 95 \%$ CI $28.5-41.1)$ compared to those with no contacts in the past 6 months $(20.8 \%, 95 \%$ CI 20.0-21.6). Similarly, a person belonging to the same ward/village/ neighbourhood with a confirmed COVID-19 case in the last 6 months, had higher chances of being seropositive (28.3\% 95\% CI 25.7-31.1) compared to their counterparts (21.0\%, 95\% CI 20.2-21.9) (Table 2).

There was a wide district-level differential in seropositivity ranging from $10.7 \%$ [95\% CI 9.0-12.7] in Moradabad to $28.1 \%$ [95\% CI 25.6-30.7] in Agra and 33.0\% [95\% CI 30.4-35.7] in Varanasi (Fig. 1). Seropositivity ranged from 10.0 to $47.5 \%$ in urban areas and $4.5-20.8 \%$ in rural areas across the districts. Except for Kaushambi and Baghpat 
Table 1 Participant profile

\begin{tabular}{|c|c|}
\hline Characteristics & Participants, $n(\%)$ \\
\hline Total & $16,012(100.0)$ \\
\hline \multicolumn{2}{|l|}{ Residence } \\
\hline Urban & $7000(47.0)$ \\
\hline Rural & $9012(53.0)$ \\
\hline \multicolumn{2}{|l|}{ Household size } \\
\hline$<5$ & $3877(25.1)$ \\
\hline $5-6$ & $6227(39.1)$ \\
\hline $7+$ & $5494(33.0)$ \\
\hline Missing & $414(2.8)$ \\
\hline Mean household size (SD) $(n=15,598)$ & $6.2(2.7)$ \\
\hline \multicolumn{2}{|l|}{ Age, years } \\
\hline $5-17$ years & $3493(21.3)$ \\
\hline $18+$ years & $12,519(78.7)$ \\
\hline $18-39$ years & $7601(48.6)$ \\
\hline $40-59$ years & $4378(27.3)$ \\
\hline $60+$ years & $540(2.9)$ \\
\hline Median age, years (25th, 75th) & $30(19,40)$ \\
\hline \multicolumn{2}{|l|}{ Gender } \\
\hline Male & $8253(51.2)$ \\
\hline Female & $7759(48.8)$ \\
\hline \multicolumn{2}{|l|}{ Current occupation (aged 18+) $(n=12,519)$} \\
\hline Professionals & $696(5.5)$ \\
\hline Business & $1936(18.2)$ \\
\hline Agricultural & $3234(23.0)$ \\
\hline Housewife & 4119 (31.9) \\
\hline Unemployed & $1334(12.3)$ \\
\hline Other & $860(6.5)$ \\
\hline Missing & $340(2.8)$ \\
\hline Government employee (among aged $18+)(n=12,519)$ & $229(1.6)$ \\
\hline Working outside of home district (among aged $18+$ and working) $(n=6726)$ & $279(3.9)$ \\
\hline Work place was under containment zone/in hotspot areas in last 6 months (among aged $18+$ and working) $(n=6726)$ & $597(10.8)$ \\
\hline \multicolumn{2}{|l|}{ Travelled for work or other purposes in last 6 months (among aged 18+) $(n=12,519)$} \\
\hline Travelled within district & $2273(16.8)$ \\
\hline Travelled between districts & $383(2.5)$ \\
\hline Travelled to other state or abroad & $83(0.4)$ \\
\hline Had any comorbidity (among aged $18+)(n=12,519)$ & $485(3.7)$ \\
\hline Smoking (among aged $18+)(n=12,519)$ & $1385(10.0)$ \\
\hline History of COVID-19-positive of any household member in last 6 months & $137(1.2)$ \\
\hline History of COVID-19-positive of any household member at the time of survey & $29(0.4)$ \\
\hline History of COVID-19-positive of any person from this village/ward or neighbourhood in last 6 months & $1414(8.2)$ \\
\hline History of contact with an individual diagnosed with COVID in last 6 months & $162(1.6)$ \\
\hline
\end{tabular}

districts, we found higher seropositivity in urban areas compared to rural areas. Furthermore, it was observed that in certain districts, including Varanasi, Agra, Kanpur Nagar, Prayagraj, Kaushambi and Moradabad, the seropositivity was similar among 5-17 years and 18+ years whereas in the rest of the districts the seropositivity was slightly higher among adults compared to the younger population.
Findings presented in Fig. 2a show that $5.1 \%$ of PSUs had zero seroprevalence whereas $54.0 \%$ and $41.0 \%$ PSUs had at least $20 \%$ or more than $20 \%$ seroprevalence, respectively. In addition, $38.6 \%$ of rural PSUs had seropositivity more than the overall level of rural seropositivity, while $47.5 \%$ of urban PSUs had seropositivity more than the overall level of urban seropositivity. Seropositivity levels 
Table 2 Seroprevalence [95\% CI] by characteristics of participants in UP

\begin{tabular}{|c|c|c|c|c|c|}
\hline Characteristics & Participants, $n$ & $\begin{array}{l}\text { Seropositive } \\
\text { participants, } \\
n\end{array}$ & $\begin{array}{l}\text { Unweighted sero- } \\
\text { prevalence, } \%[95 \% \\
\text { CI] }\end{array}$ & $\begin{array}{l}\text { Weighted sero- } \\
\text { prevalence, } \% \\
{[95 \% \mathrm{CI}]}\end{array}$ & $\begin{array}{l}\text { Weighted seroprevalence adjusted } \\
\text { for test performance }{ }^{+}, \%[95 \% \mathrm{CI}\end{array}$ \\
\hline Total & 16,012 & 3332 & 20.8 [20.2-21.4] & $22.1[21.5-22.8]$ & 22.2 [21.5-22.9] \\
\hline \multicolumn{6}{|l|}{ Residence } \\
\hline Urban & 9012 & 1411 & 27.4 [26.4-28.5] & 29.7 [28.7-30.7] & 30.6 [29.4-31.7] \\
\hline Rural & 7000 & 1921 & $15.7[14.9-16.4]$ & $15.4[14.7-16.2]$ & $14.7[13.9-15.6]$ \\
\hline \multicolumn{6}{|l|}{ Household size } \\
\hline$<5$ & 3877 & 830 & $21.4[20.2-22.7]$ & $23.1[21.8-24.5]$ & $23.3[21.9-24.8]$ \\
\hline $5-6$ & 6227 & 1257 & $20.2[19.2-21.2]$ & $22.0[21.0-23.0]$ & $22.0[20.9-23.2]$ \\
\hline $7+$ & 5494 & 1168 & $21.3[20.2-22.4]$ & 21.5 [20.4-22.6] & $21.5[20.3-22.7]$ \\
\hline \multicolumn{6}{|l|}{ Age } \\
\hline 5-17 years & 3493 & 622 & $17.8[16.6-19.1]$ & 18.7 [17.4-20.1] & 18.4 [17.0-19.9] \\
\hline $18+$ years & 12519 & 2710 & 21.7 [20.9-22.4] & $23.1[22.3-23.8]$ & $23.2[22.4-24.0]$ \\
\hline $18-39$ years & 7601 & 1597 & 21.0 [20.1-21.9] & $22.4[21.5-23.3]$ & 22.5 [21.4-23.5] \\
\hline $40-59$ years & 4378 & 948 & 22.5 [21.3-23.7] & $24.1[22.8-25.3]$ & 24.3 [22.9-25.7] \\
\hline $60+$ years & 540 & 129 & 23.9 [20.5-27.7] & $25.0[21.3-29.2]$ & 25.4 [21.3-30.0] \\
\hline \multicolumn{6}{|l|}{ Gender } \\
\hline Male & 8253 & 1749 & $21.2[20.3-22.1]$ & $22.1[21.2-23]$ & $22.2[21.2-23.2]$ \\
\hline Female & 7759 & 1583 & 20.4 [19.5-21.3] & $22.2[21.2-23.1]$ & $22.2[21.2-23.2]$ \\
\hline \multicolumn{6}{|c|}{ Current occupation (aged 18+) } \\
\hline Professionals & 696 & 529 & $24.0[21.0-27.3]$ & $25.0[21.9-28.4]$ & $25.4[22.0-29.1]$ \\
\hline Business & 1936 & 1395 & $27.9[26.0-30.0]$ & $27.9[26.1-29.8]$ & $28.6[26.6-30.6]$ \\
\hline Agricultural & 3234 & 2629 & $18.7[17.4-20.1]$ & $18.4[17.1-19.9]$ & $18.1[16.6-19.7]$ \\
\hline Housewife & 4119 & 3251 & $21.1[19.9-22.4]$ & $24.1[22.8-25.4]$ & $24.3[22.9-25.8]$ \\
\hline Unemployed & 1334 & 1027 & $23.0[20.8-25.4]$ & $23.5[21.4-25.6]$ & $23.7[21.4-26.1]$ \\
\hline Others & 860 & 701 & $18.5[16.0-21.2]$ & $18.8[16.2-21.6]$ & $18.5[15.7-21.6]$ \\
\hline \multicolumn{6}{|l|}{$\begin{array}{l}\text { Government employee (aged } \\
18+\text { ) }\end{array}$} \\
\hline Yes & 229 & 50 & $21.8[17.0-27.7]$ & $18.1[13.5-24.0]$ & $17.8[12.6-24.2]$ \\
\hline No & 11,950 & 2597 & $21.7[21.0-22.5]$ & $23.2[22.4-23.9]$ & $23.3[22.5-24.2]$ \\
\hline \multicolumn{6}{|c|}{$\begin{array}{l}\text { Work place (aged } 18+\text { and work- } \\
\text { ing) }\end{array}$} \\
\hline Working in home district & 6447 & 1408 & $21.8[17.0-27.7]$ & $18.1[13.5-24.0]$ & $17.8[12.6-24.2]$ \\
\hline $\begin{array}{l}\text { Working outside of home } \\
\text { district }\end{array}$ & 279 & 64 & 21.9 [20.9-22.9] & $22.5[21.5-23.6]$ & $22.6[21.5-23.8]$ \\
\hline \multicolumn{6}{|c|}{$\begin{array}{l}\text { Work place came under contain- } \\
\text { ment zone/fall in hotspot areas } \\
(\text { aged } 18+)\end{array}$} \\
\hline Yes & 597 & 139 & $23.3[20.1-26.8]$ & 25.6 [22.6-28.9] & 26.0 [22.7-29.7] \\
\hline No & 5385 & 1149 & $21.3[20.3-22.5]$ & $21.6[20.5-22.7]$ & 21.6 [20.3-22.9] \\
\hline Don’t know & 744 & 184 & $24.7[21.8-28.0]$ & 24.1 [21.6-26.9] & 24.4 [21.5-27.5] \\
\hline \multicolumn{6}{|c|}{$\begin{array}{l}\text { Travelled within district for } \\
\text { work or other purposes in last } \\
6 \text { months (aged } 18+\text { ) }\end{array}$} \\
\hline Yes & 2273 & 498 & $21.9[20.3-23.7]$ & $21.2[19.5-23.0]$ & $21.1[19.3-23.1]$ \\
\hline No & 10,246 & 2212 & $21.6[20.8-22.4]$ & 23.4 [22.6-24.2] & $23.6[22.7-24.5]$ \\
\hline \multicolumn{6}{|l|}{$\begin{array}{l}\text { Travelled between districts for } \\
\text { work or other purpose in last } \\
6 \text { months (aged } 18+\text { ) }\end{array}$} \\
\hline Yes & 383 & 87 & $22.7[18.8-27.2]$ & $21.3[17.1-26.2]$ & $21.3[16.6-26.6]$ \\
\hline No & 12,136 & 2623 & $21.6[20.9-22.4]$ & $23.1[22.4-23.9]$ & $23.3[22.4-24.1]$ \\
\hline
\end{tabular}


Table 2 (continued)

\begin{tabular}{|c|c|c|c|c|c|}
\hline Characteristics & Participants, $n$ & $\begin{array}{l}\text { Seropositive } \\
\text { participants, } \\
n\end{array}$ & $\begin{array}{l}\text { Unweighted sero- } \\
\text { prevalence, } \%[95 \% \\
\text { CI] }\end{array}$ & $\begin{array}{l}\text { Weighted sero- } \\
\text { prevalence, \% } \\
{[95 \% \mathrm{CI}]}\end{array}$ & $\begin{array}{l}\text { Weighted seroprevalence adjusted } \\
\text { for test performance }{ }^{+}, \%[95 \% \mathrm{CI}]\end{array}$ \\
\hline \multicolumn{6}{|c|}{$\begin{array}{l}\text { Travelled to other state or abroad } \\
\text { for work or other purposes in } \\
\text { last } 6 \text { months (aged } 18+\text { ) }\end{array}$} \\
\hline Yes & 83 & 16 & $19.3[12.2-29.2]$ & $18.6[10.4-31.1]$ & $18.3[09.2-32.1]$ \\
\hline No & 12,436 & 2694 & $21.7[21.0-22.4]$ & $23.1[22.3-23.8]$ & $23.2[22.4-24.1]$ \\
\hline \multicolumn{6}{|c|}{ Had any comorbidity (aged $18+$ ) } \\
\hline Yes & 485 & 121 & $25.0[21.3-29.0]$ & $25.4[21.7-29.6]$ & $25.8[21.7-30.4]$ \\
\hline No & 12,034 & 2589 & $21.5[20.8-22.3]$ & $23.0[22.2-23.7]$ & $23.1[22.3-23.9]$ \\
\hline \multicolumn{6}{|c|}{ Smoking (aged 18+) } \\
\hline Yes & 1385 & 310 & $22.4[20.3-24.7]$ & $22.6[20.4-25.0]$ & $22.8[20.3-25.4]$ \\
\hline No & 10,794 & 2337 & $21.7[20.9-22.4]$ & $23.1[22.3-23.9]$ & $23.3[22.4-24.2]$ \\
\hline \multicolumn{6}{|c|}{$\begin{array}{l}\text { History of COVID-19-positive of } \\
\text { any household member in last } \\
6 \text { months }\end{array}$} \\
\hline Yes & 137 & 46 & 33.6 [26.2-41.9] & $38.8[32.2-45.9]$ & $40.6[33.3-48.5]$ \\
\hline No & 15,461 & 3209 & $20.8[20.1-21.4]$ & $21.9[21.3-22.6]$ & $21.9[21.2-22.7]$ \\
\hline \multicolumn{6}{|c|}{$\begin{array}{l}\text { History of COVID-19-positive of } \\
\text { any household member at the } \\
\text { time of survey }\end{array}$} \\
\hline Yes & 29 & 7 & $24.1[12.0-42.7]$ & $27.1[17.6-39.4]$ & $27.7[17.1-41.3]$ \\
\hline No & 15,569 & 3248 & $20.9[20.2-21.5]$ & 22.1 [21.4-22.7] & 22.1 [21.4-22.9] \\
\hline \multicolumn{6}{|c|}{$\begin{array}{l}\text { History of COVID-19-positive } \\
\text { of any person from this village/ } \\
\text { ward or neighbourhood in last } \\
6 \text { months }\end{array}$} \\
\hline Yes & 1414 & 362 & 25.6 [23.4-27.9] & 27.7 [25.3-30.2] & $28.3[25.7-31.1]$ \\
\hline No & 12,122 & 2430 & 20.1 [19.3-20.8] & 21.1 [20.4-21.9] & 21.0 [20.2-21.9] \\
\hline Don’t know & 2062 & 463 & 22.5 [20.7-24.3] & $23.8[22.2-25.5]$ & $24.1[22.3-25.9]$ \\
\hline \multicolumn{6}{|c|}{$\begin{array}{l}\text { History of contact with any of } \\
\text { the COVID-19-positives in last } \\
6 \text { months }\end{array}$} \\
\hline Yes & 162 & 55 & $34.0[27.1-41.6]$ & $33.3[27.8-39.2]$ & $34.5[28.5-41.1]$ \\
\hline No & 12,101 & 2372 & 19.6 [18.9-20.3] & 20.9 [20.1-21.6] & $20.8[20.0-21.6]$ \\
\hline Don’t know & 3335 & 828 & 24.8 [23.4-26.3] & 24.9 [23.6-26.2] & $25.2[23.8-26.7]$ \\
\hline
\end{tabular}

${ }^{+}$adjusted for test performance (sensitivity $92.37 \%$ and specificity $97.9 \%$ )

did not vary by the PSU size (Fig. 2b). Table 3 presents the participant's characteristics among the three PSU clusters with no, moderate and high seropositivity. In high seropositivity PSUs, a relatively larger proportion of participants were from urban areas (70\%), engaged in business $(25.0 \%)$ and their workplace fell under a containment zone (13.1\%). Also, PSUs with higher seropositivity had a higher proportion of persons $(10.5 \%)$ reporting a confirmed case of COVID-19 person from their community in the 6 months preceding the survey compared to PSUs with moderate seropositivity PSUs (6.8\%) and PSUs with no seropositivity $(1.7 \%)$.

\section{Discussion}

Our study was the first seroepidemiological study in UP which provides district-level estimates of SARS-CoV-2 antibodies in high-burden districts of UP. We found that $22.2 \%$ of the population, equating to 10.4 million people in 11 districts, was exposed to SARS-CoV-2 infection by early September 2020. We also identified significant heterogeneity across the state with seroprevalence ranging from 10.7 to $33.0 \%$.

A few other states in India, and several other countries, have conducted population-based seroprevalence studies to provide information about the situation of the epidemic from time to time. For example, the results of analysis from 38 
Overall

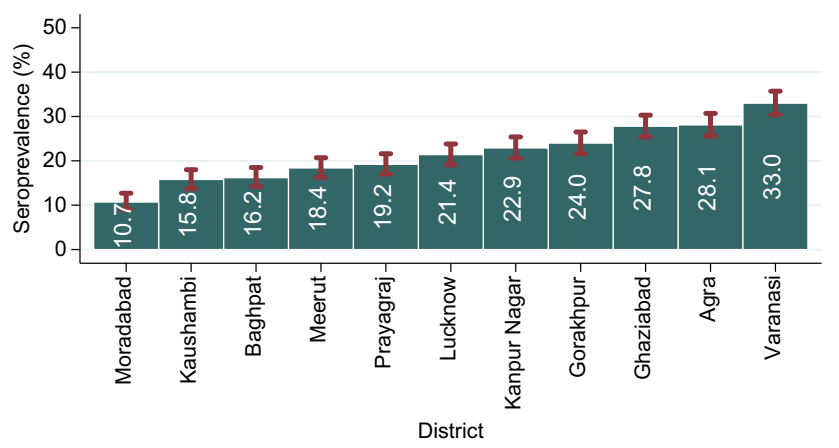

Seroprevalence $\longmapsto 95 \% \mathrm{Cl}$

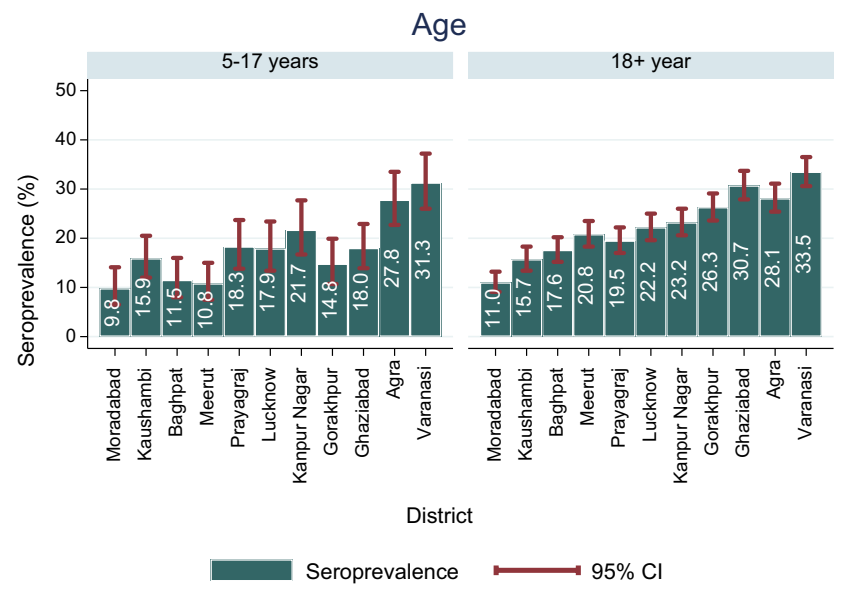

Area of residence

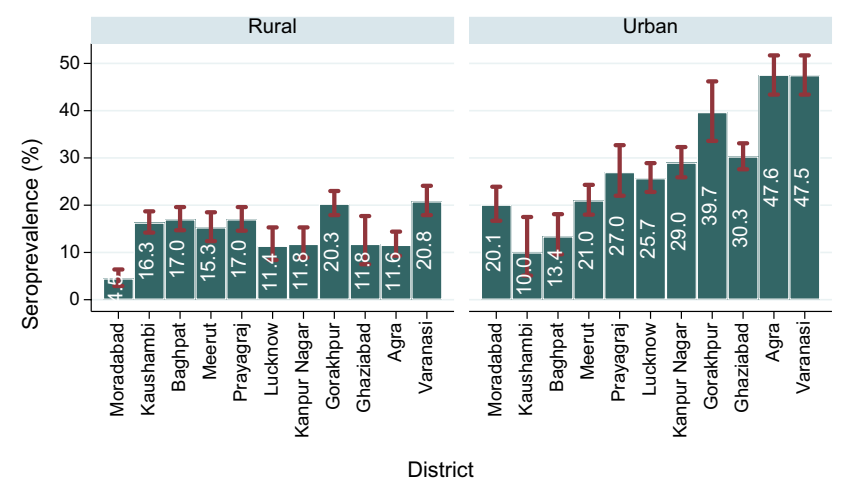

Seroprevalence $295 \% \mathrm{Cl}$

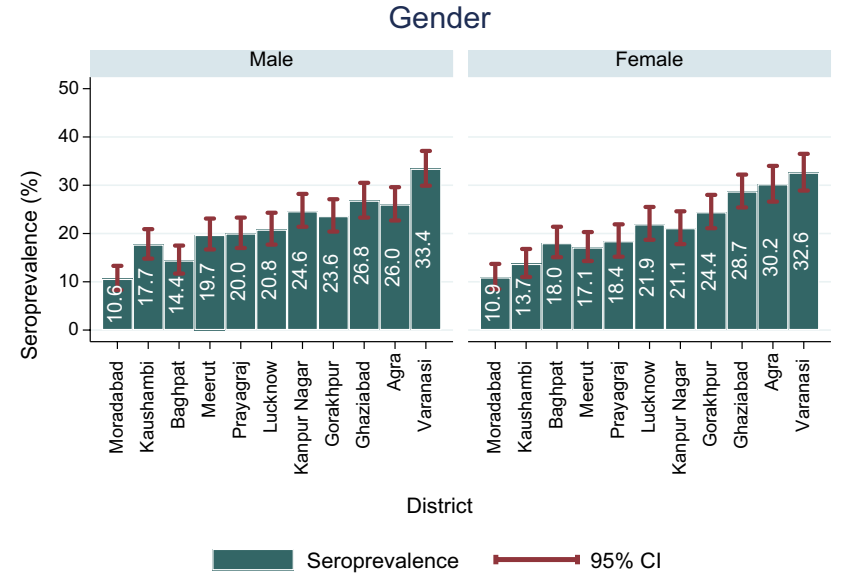

Fig. 1 Seroprevalence (\%) and 95\% CI (adjusted for test performance) in 11 districts of UP, stratified by area of residence, age group and gender

countries showed seroprevalence ranging from 0.1 to $38.1 \%$ by mid-September 2020 [27]. Similarly, studies from urban cities across India (Indore, Haryana, Chennai, Delhi, and Pune) had shown that $8-52 \%$ of the population was infected in the initial 6-8 months of the onset of the COVID-19 pandemic [28-32].

The three rounds of national serosurvey in India between May and December 2020 showed an increasing seropositivity trend. The second national serosurveillance study, conducted by ICMR at the same time period as this study, showed only $6.6 \%$ of India's population aged $10+$ years were exposed to SARS-CoV-2 by mid-September 2020. In the nine districts of UP that were included in the national seroprevalence survey, a low prevalence was detected, ranging from $1 \%$ in Aurayia to $13 \%$ in Mau district, suggesting that these districts were in the early phases of the epidemic [12]. In contrast, our study revealed a higher seroprevalence in the 11 districts in which our study was implemented, indicating a more advanced stage of the epidemic by mid-September 2020. The differences in the estimates provided by the ICMR study and our study are likely to be attributed to the differences in the sampling design. Our study included a larger sample (1440) per district to provide representative district-level estimates, whereas the ICMR study was designed to provide national estimate covering 400 samples from selected districts. Also, the higher sample size in this study allowed us to provide representative district-level rural-urban estimates, which was not the purpose of the national serosurveillance study. 
Fig. 2 Distribution of PSUs according to seroprevalence (a) and seroprevalence in PSUs by area of residence (b), $n=493$. Circle represents population size of the PSUs (278 Rural PSUs and 215 Urban PSus)
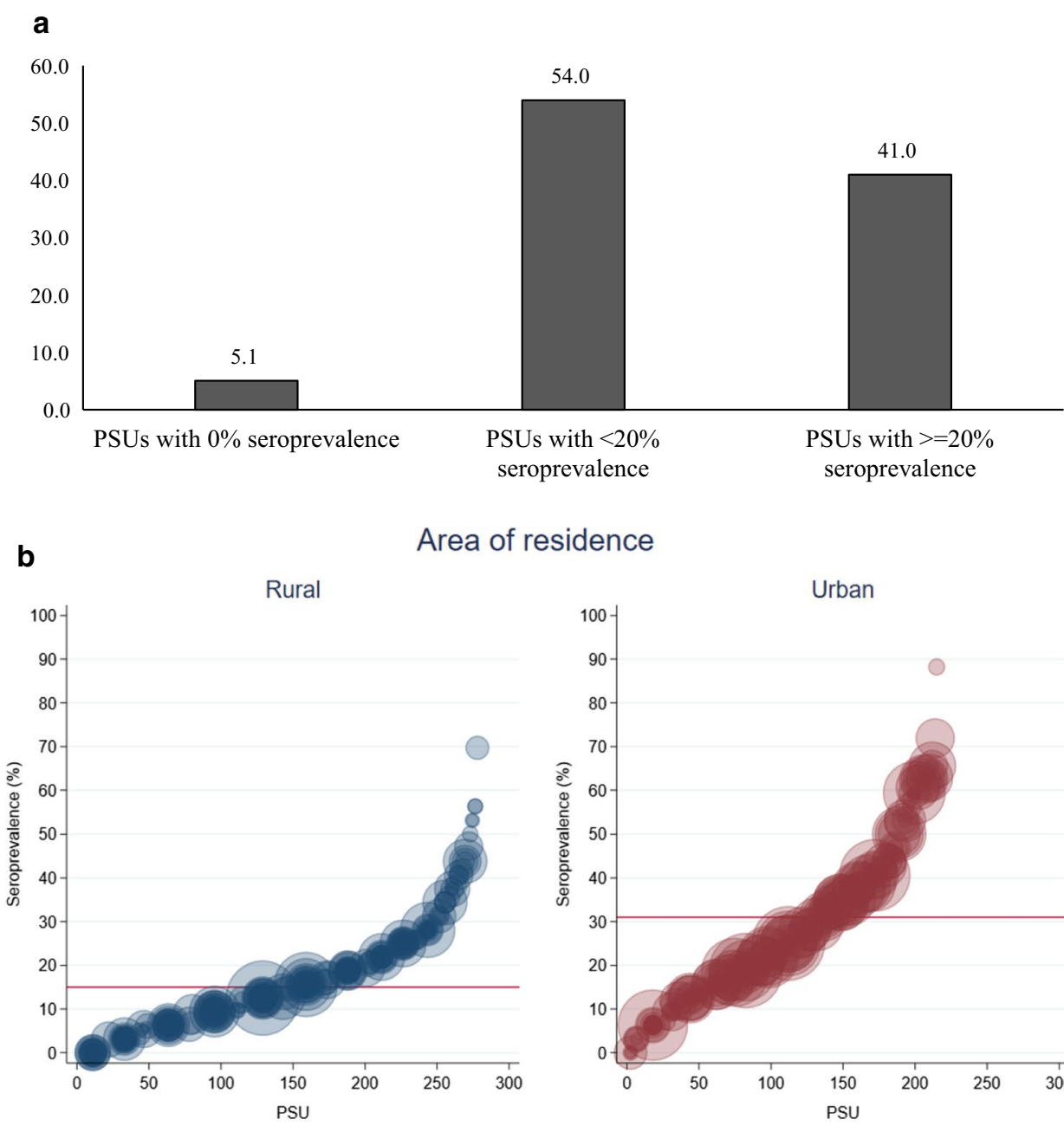

Area of residence

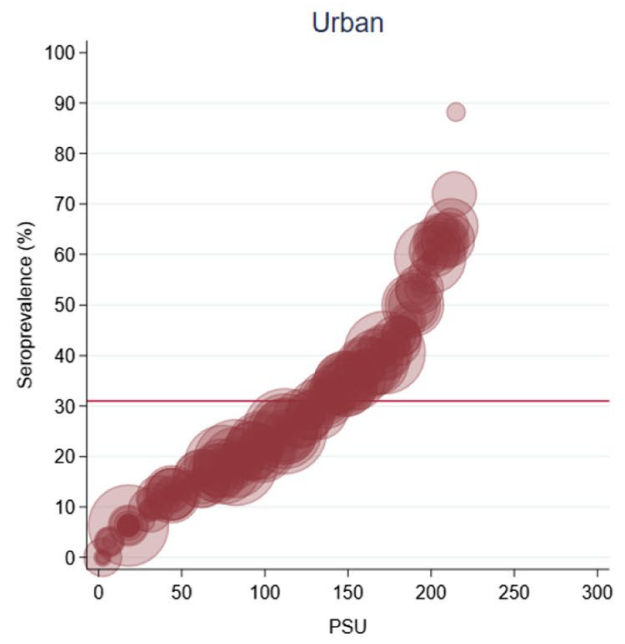

The results also confirmed a distinctly higher exposure to SARS-CoV-2 in urban areas compared to rural areas until September 2020. Other studies conducted in India also reported lower seroprevalence in rural areas (5.2\%) compared to urban areas (9.0\% in urban non-slum and $16.9 \%$ in urban slum areas) [12]. Moreover, serosurveyes in other Indian cities estimated seropositivity as high as $51.3 \%$ in Pune city, $54.1 \%$ and $16.1 \%$ in urban slum and non-slum areas in Mumbai city, 23.2\% in Ahmedabad city and 22.9\% in Delhi $[12,16-18]$. Urban areas are densely populated with less well ventilated and compact houses and have higher population mobility as compared to rural areas, both factors likely contributing to higher transmissibility [33]. The higher proportion of the unexposed population (78\%) in these 11 districts, necessitates the need for continuous monitoring and focused testing.
The present study was uniquely designed to provide a representative estimate of seropositivity by gender and age. Based on the overall adjusted seroprevalence, the younger population (age 5-17 years) had less exposure to the SARSCoV-2 infection compared to the adult or elderly population. We found no significant difference in seropositivity between men and women. A similar pattern was also observed at the national level [12] wherein men and women had similar seroprevalence and adults and elderly had relatively higher (though not statistically significant) seroprevalence. There is limited availability of sex and age disaggregated data in India, thus hampering analysis of gendered implications of COVID-19. Evidence on the gender and age disaggregated COVID-19 was largely mixed in nature with few studies showing a greater occurrence of infection in men while 
Table 3 Profile of participants by PSU clusters according to seroprevalence

\begin{tabular}{|c|c|c|c|c|}
\hline \multirow[t]{2}{*}{ Characteristics } & \multicolumn{3}{|c|}{ PSU clusters based on seroprevalence } & \multirow[t]{2}{*}{$p$ value } \\
\hline & $\begin{array}{l}\text { PSUs with } 0 \% \\
\text { seroprevalence } \\
(n=795)\end{array}$ & $\begin{array}{l}\text { PSUs with }<20 \% \\
\text { seroprevalence } \\
(N=8668)\end{array}$ & $\begin{array}{l}\text { PSUs with } \geq 20 \% \\
\text { seroprevalence } \\
(N=6549)\end{array}$ & \\
\hline Residing in urban areas & 13.1 & 30.7 & 70.1 & 0.000 \\
\hline Mean household size (SD) & $6.2(2.4)$ & $6.3(2.8)$ & $6.0(2.7)$ & 0.000 \\
\hline Mean age, years (SD) & $31.3(15.0)$ & $30.9(14.7)$ & $31.2(14.5)$ & 0.307 \\
\hline Male & 52.8 & 51.0 & 51.3 & 0.483 \\
\hline Current occupation (aged 18+) & & & & 0.000 \\
\hline Professionals & 2.7 & 6.0 & 5.1 & \\
\hline Business & 5.6 & 13.4 & 25.0 & \\
\hline Agricultural & 48.2 & 27.5 & 15.0 & \\
\hline Housewife & 29.1 & 32.5 & 31.4 & \\
\hline Unemployed & 5.1 & 11.4 & 14.2 & \\
\hline Others & 9.1 & 2.6 & 3.3 & \\
\hline Government employee (among aged 18+) & 1.2 & 1.5 & 1.8 & 0.072 \\
\hline $\begin{array}{l}\text { Working in other than home district (among aged } 18+\text { and work- } \\
\text { ing) }\end{array}$ & 1.7 & 4.1 & 4.0 & 0.011 \\
\hline $\begin{array}{l}\text { Work place came under containment zone/fall in hotspot areas in } \\
\text { last } 6 \text { months (among aged } 18+\text { and working) }\end{array}$ & 0.1 & 10.1 & 13.1 & 0.000 \\
\hline $\begin{array}{l}\text { Travelled within district for work or other purposes in last } \\
6 \text { months (among aged } 18+\text { ) }\end{array}$ & 14.4 & 19.7 & 13.7 & 0.005 \\
\hline $\begin{array}{l}\text { Travelled between districts for work or other purposes in last } \\
6 \text { months (among aged } 18+\text { ) }\end{array}$ & 2.0 & 2.5 & 2.5 & 0.175 \\
\hline $\begin{array}{l}\text { Travelled to other state or abroad for work or other purposes in } \\
\text { last } 6 \text { months (among aged } 18+\text { ) }\end{array}$ & 0.3 & 0.5 & 0.4 & 0.983 \\
\hline Had any comorbidity (among aged $18+$ ) & 0.4 & 3.6 & 4.1 & 0.000 \\
\hline Smoking (among aged 18+) & 6.2 & 10.5 & 9.9 & 0.021 \\
\hline $\begin{array}{l}\text { History of COVID-19-positive of any household member in last } \\
6 \text { months }\end{array}$ & 0.3 & 1.0 & 1.5 & 0.052 \\
\hline $\begin{array}{l}\text { History of COVID-19-positive of any household member at the } \\
\text { time of survey }\end{array}$ & 0.3 & 0.5 & 0.3 & 0.391 \\
\hline $\begin{array}{l}\text { History of COVID-19-positive of any person from this village/ } \\
\text { ward or neighbourhood in last } 6 \text { months }\end{array}$ & 1.7 & 6.8 & 10.5 & 0.000 \\
\hline $\begin{array}{l}\text { History of contact with any of the COVID-19-positives in last } \\
6 \text { months }\end{array}$ & 0.1 & 0.9 & 2.6 & 0.000 \\
\hline
\end{tabular}

others found a similar distribution of infection by gender with some variation across age group $[4,11,12]$.

Furthermore, the study found large geographical heterogeneity in seroprevalence across the PSUs covered in the study. The PSU-level seroprevalence ranged from 0 to $88.2 \%$ in urban areas and 0 to $69.7 \%$ in rural areas. We also assessed the PSU-level heterogeneity in seropositivity to understand the differential in the characteristic of the geographies with no-seropositivity versus medium or high level of seropositivity. Clearly, the PSUs with high seropositivity had a larger proportion of the population with a larger exposure to COVID-19 compared to moderate and no-seropositivity PSUs. These findings bring evidence for the need to adopt a differential geography-specific containment, surveillance and treatment strategy. While a robust surveillance method and high testing levels are important for geographies with lower seropositivity, it is also important to ensure that these areas are suitably equipped with proper treatment facilities. Due to their heightened vulnerability to any potential escalation in cases, it is vital to ensure service readiness to avoid sudden overstraining of the healthcare system. On the other hand, in high prevalence geographies, there is a need to continue priority testing of symptomatic individuals and patients with co-morbidities and contacts of confirmed cases. Disease management strategies in such regions can also serve as a template for newer geographies of focus, 
where the virus spread is still in a relatively nascent stage. For example, if facility-based clinical management is only required for a select demographic group or people with co-morbidities, then these learnings should be utilised to further inform home treatment policies and protocols. This could ease pressure on health service system resources so that critical cases could be managed properly.

The present serosurveillance study has certain limitations. Although the study provides district-level representative estimates, the seroprevalence estimates cannot be generalized for the whole state as the 11 districts were not randomly selected. Second, similar to other studies, the prevalence estimates can be affected by the test specificity. Third, since the study included only one respondent from the selected household, the effect of household size on seropositivity cannot be ascertained. Lastly, we may have missed some people with very recent infection as their $\operatorname{IgG}$ might not have developed during the acute phase of the disease at the time of the survey. However, despite these limitations, the first seroprevalence study in the state provides important information about the population already exposed to SARS-CoV-2 infection versus those susceptible to infection. A repeat cross-sectional survey may help to shed light on the evolving trajectory of the virus, as well as the effectiveness of the existing disease monitoring and management systems. Along with strengthening sentinel surveillance, as the risk of COVID-19 changes over time, such exercises will aid the state and local administration in formulating disease management and containment planning strategies to the best needs of the local populace. Furthermore, the findings are of considerable assistance as the state works to resume service in other priority health domains to pre-COVID levels. A repeat seroprevalence study among COVID positive cases may also be able to provide insight about the duration until which antibodies persist.

\section{Conclusion}

Since the onset of the COVID-19 pandemic, India has witnessed a concentration of a higher number of positive cases in certain geographies. Population-based serosurveys aid not only in identifying the proportion of population infected but also as an estimate of the remaining susceptible population, thus providing valuable information for future planning and mitigation efforts to contain further spread. We found that nearly one in five individuals aged five and above were exposed to SARS-CoV-2 infection in UP by mid-September 2020 when the state witnessed its first peak. The findings also indicate that a substantial proportion of the population in 11 districts remain susceptible. Therefore, targeted contact tracing and testing remain critical to control the transmission of the virus. Moreover, the health facilities need to be continuously monitored to ensure that the facilities providing COVID management are prepared. Recognizing the fact that India, as well as UP, is currently witnessing a second wave of the epidemic, another round of seroprevalence survey and/or a seroconversion survey among already infected individuals might additionally give insights into disease epidemiology. Ascertaining the geographies wherein susceptibility among the general populace is greater would help in informing strategic allocation of resources by the government. The study also offers an example of a plausible methodology to conduct the state-specific serosurveys to those states which are yet to conduct such state-level serosurveys.

\section{Appendix}

See Table 4 and Fig. 3.

Table 4 Weighted seroprevalence [95\% CI] adjusted for test performance by place of residence, age group and gender in 11 districts of UP

\begin{tabular}{|c|c|c|c|c|c|c|c|}
\hline & \multirow[t]{2}{*}{ Overall } & \multicolumn{2}{|l|}{ Place of residence } & \multicolumn{2}{|l|}{ Age group } & \multicolumn{2}{|l|}{ Gender } \\
\hline & & Urban & Rural & 5-17 years & $18+$ years & Male & Female \\
\hline Agra & $28.1[25.6-30.7]$ & $47.6[43.4-51.7]$ & $11.6[9.3-14.4]$ & $27.8[22.7-33.5]$ & $28.1[25.4-31.1]$ & $26.0[22.7-29.6]$ & 30.2 [26.6-34] \\
\hline Baghpat & $16.2[14.2-18.5]$ & $13.4[9.6-18.1]$ & 17.0 [14.7-19.6] & $11.5[8-16]$ & $17.6[15.2-20.2]$ & $14.4[11.7-17.5]$ & $18.0[15.1-21.4]$ \\
\hline Ghaziabad & $27.8[25.4-30.3]$ & 30.3 [27.6-33.1] & 11.8 [7.5-17.7] & 18.0 [13.9-22.9] & 30.7 [27.9-33.7] & 26.8 [23.3-30.5] & $28.7[25.4-32.2]$ \\
\hline Gorakhpur & 24.0 [21.6-26.5] & 39.7 [33.6-46.2] & 20.3 [17.9-23] & 14.8 [10.7-19.9] & $26.3[23.6-29.1]$ & $23.6[20.4-27.1]$ & 24.4 [21.1-28] \\
\hline Kanpur nagar & $22.9[20.6-25.4]$ & 29.0 [25.9-32.3] & 11.8 [8.9-15.3] & 21.7 [16.7-27.7] & 23.2 [20.6-26] & 24.6 [21.4-28.2] & 21.1 [17.8-24.6] \\
\hline Kaushambi & $15.8[13.7-18]$ & $10.0[5.1-17.5]$ & 16.3 [14.2-18.7] & $15.9[12-20.5]$ & $15.7[13.4-18.3]$ & 17.7 [14.8-20.9] & $13.7[11-16.8]$ \\
\hline Lucknow & $21.4[19.1-23.8]$ & 25.7 [22.8-28.9] & $11.4[8.4-15.3]$ & $17.9[13.4-23.4]$ & 22.2 [19.6-25] & 20.8 [17.7-24.3] & 21.9 [18.7-25.5] \\
\hline Meerut & 18.4 [16.3-20.7] & 21.0 [18-24.3] & $15.3[12.4-18.5]$ & $10.8[7.5-15]$ & 20.8 [18.3-23.5] & $19.7[16.7-23.1]$ & $17.1[14.3-20.3]$ \\
\hline Moradabad & 10.7 [9-12.7] & 20.1 [16.7-23.9] & 4.5 [2.9-6.4] & $9.8[6.5-14.1]$ & $11.0[9.1-13.2]$ & $10.6[8.3-13.3]$ & $10.9[8.5-13.7]$ \\
\hline Prayagraj & 19.2 [17-21.6] & $27.0[22-32.7]$ & $17.0[14.6-19.6]$ & $18.3[13.8-23.7]$ & $19.5[17-22.2]$ & $20.0[17-23.3]$ & 18.4 [15.2-21.9] \\
\hline Varanasi & $33.0[30.4-35.7]$ & $47.5[43.4-51.7]$ & $20.8[17.9-24.1]$ & $31.3[26-37.2]$ & $33.5[30.6-36.5]$ & 33.4 [29.9-37.1] & 32.6 [28.9-36.5] \\
\hline
\end{tabular}




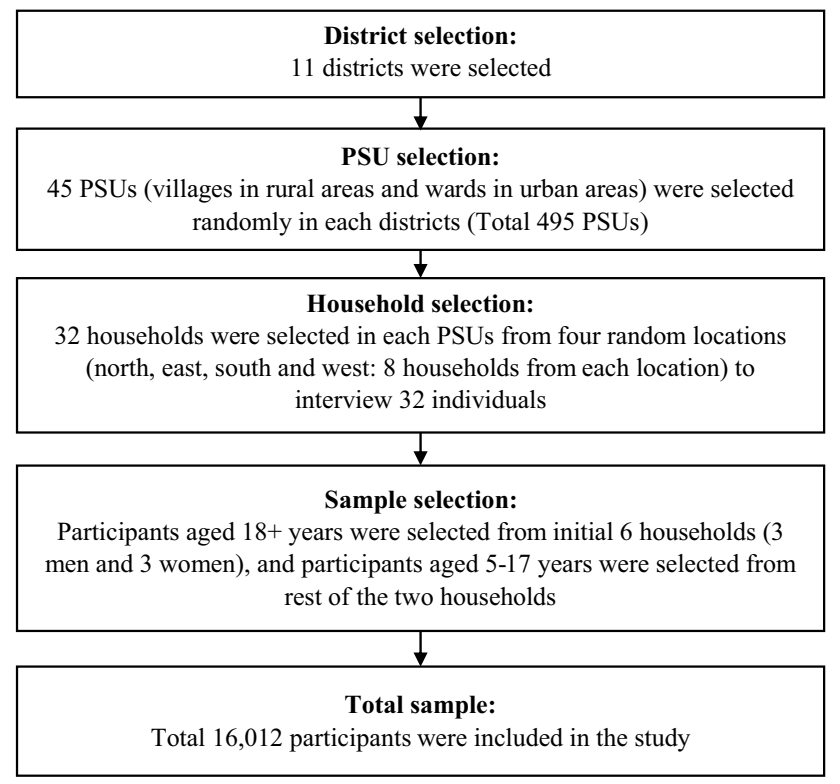

Fig. 3 Framework of sample selection

\begin{abstract}
Acknowledgements We thank all the study participants and the survey implementation team who supported this study. We also thank the Uttar Pradesh state government for providing the necessary approvals to conduct this study. We would also like to acknowledge the support of Dr. Ashish Mishra, Dr. Chhavi Sodhi, Dr. Rajiv Ranjan, Mr. Santosh Kumar Singh, and Mr. Vivek Kumar Sharma at India Health Action Trust, Dr. Mohit Kumar Singh at Government of Uttar Pradesh, and Dr. Suruchi Shukla from the KGMU, Lucknow.
\end{abstract}

Author contributions VN, AJ, VA, RP, SI, AMP were involved in the conceptualisation, designing and supervision of the data collection. VN, RP, BD, SI, MB, JB apprehended the idea. RP, BD compiled the data and performed the analysis. VN, AJ, RP, BD, MB, SI synthesized the findings and wrote the paper. All authors read and approved the final manuscript.

Funding The UPTSU is funded by the Bill and Melinda Gates Foundation (BMGF) for providing techno-managerial support to the Government of UP. KGMU is an academic and research institution funded by the government. The funding agency did not play any role in the design of the study, data collection, analysis, interpretation or writing of the results. The views expressed herein are those of the authors and do not necessarily reflect the official policy or position of the BMGF or the Government of Uttar Pradesh.

\section{Declarations}

Conflict of interest The authors declare that they have no competing interests.

Research data The datasets used and/or analysed during the current study are available from the corresponding author after the GoUP permission on reasonable request.
Open Access This article is licensed under a Creative Commons Attribution 4.0 International License, which permits use, sharing, adaptation, distribution and reproduction in any medium or format, as long as you give appropriate credit to the original author(s) and the source, provide a link to the Creative Commons licence, and indicate if changes were made. The images or other third party material in this article are included in the article's Creative Commons licence, unless indicated otherwise in a credit line to the material. If material is not included in the article's Creative Commons licence and your intended use is not permitted by statutory regulation or exceeds the permitted use, you will need to obtain permission directly from the copyright holder. To view a copy of this licence, visit http://creativecommons.org/licenses/by/4.0/.

\section{References}

1. World Health Organization (WHO). Timeline: WHO's COVID-19 Response [Internet]. Geneva: World Health Organisation; 2020. https://www.who.int/emergencies/diseases/novel-coronavirus2019/interactive-timeline/. Accessed 13 Apr 2021.

2. World Health Organization (WHO). WHO coronavirus disease (COVID-19) Dashboard [Internet]. 2020. https://covid19.who.int/. Accessed 13 Apr 2021.

3. Eckerle I, Meyer B. SARS-CoV-2 seroprevalence in COVID-19 hotspots. Lancet. 2020;396(10250):514-5.

4. Stringhini S, Wisniak A, Piumatti G, Azman AS, Lauer SA, Baysson $\mathrm{H}$, et al. Seroprevalence of anti-SARS-CoV-2 IgG antibodies in Geneva, Switzerland (SEROCoV-POP): a population-based study. Lancet. 2020;396(10247):313-9.

5. Peeling RW, Wedderburn CJ, Garcia PJ, Boeras D, Fongwen N, Nkengasong J, et al. Serology testing in the COVID-19 pandemic response. Lancet Infect Dis. 2020;20(9):e245-9.

6. Kumar MS, Bhatnagar T, Manickam P, Kumar VS, Rade K, Shah $\mathrm{N}$, et al. National sero-surveillance to monitor the trend of SARSCoV-2 infection transmission in India: protocol for communitybased surveillance. Indian J Med Res. 2020;151:419-23.

7. Murhekar MV, Clapham H. COVID-19 serosurveys for public health decision making. Lancet Glob Heal. 2021;9(5):e559-60.

8. Salje H, Kiem CT, Lefrancq N, Courtejoie N, Bosetti P, Paireau J, et al. Estimating the burden of SARS-CoV-2 in France. Science. 2020;369(6500):208-11.

9. Pollán M, Pérez-Gómez B, Pastor-Barriuso R, Oteo J, Hernán MA, Pérez-Olmeda M, et al. Prevalence of SARS-CoV-2 in Spain (ENE-COVID): a nationwide, population-based seroepidemiological study. Lancet. 2020;396(10250):535-44.

10. Streeck H, Hartmann G, Exner M, Schmid M. Preliminary result and conclusions of the COVID-19 case cluster study (Gangelt Municipality). 2020; https://www.land.nrw/sites/default/files/ asset/document/zwischenergebnis_covid19_case_study_gange 1t_en.pdf. Accessed 13 Apr 2021.

11. Murhekar MV, Bhatnagar T, Selvaraju S, Rade K, Saravanakumar V, Thangaraj JWV, et al. Prevalence of SARS-CoV-2 infection in India: findings from the national serosurvey, May-June 2020. Indian J Med Res. 2020;152(1 \& 2):48-60.

12. Murhekar MV, Bhatnagar T, Selvaraju S, Saravanakumar V, Thangaraj JWV, Shah N, et al. SARS-CoV-2 antibody seroprevalence in India, August-September, 2020: findings from the second nationwide household serosurvey. Lancet Glob Health. 2021;9(3):e257-66.

13. DNA. ICMR third national serosurvey: 28 crore Indians had been infected by COVID-19 [Internet]. DNA. 2021. https:// www.dnaindia.com/health/report-icmr-third-national-seros 
urvey-28-crore-indians-had-been-infected-by-covid-2873212. Accessed 13 Apr 2021.

14. The Tribune. COVID-19: $24.19 \%$ seroprevalence found in Punjab's 12 districts, finds serosurvey. The Tribune [Internet]. 2020. https://www.tribuneindia.com/news/punjab/covid-19-2419-seroprevalence-found-in-punjabs-12-districts-finds-seros urvey-182898. Accessed 13 Apr 2021.

15. Mint. Nearly $20 \%$ Andhra residents have developed antibodies to COVID-19: Sero survey. Mint [Internet]. 2020. https://www. livemint.com/news/india/nearly-20-andhra-residents-have-devel oped-antibodies-to-covid-19-sero-survey-11599797439599.html. Accessed 13 Apr 2021.

16. The Hindu. Coronavirus: Sero-survey suggests $23.24 \%$ people in Ahmedabad have COVID-19 anti-bodies. The Hindu [Internet]. 2020. https://www.thehindu.com/news/national/other-states/ ahmedabad-sero-survey-suggests-2324-pc-people-have-covid-19anti-bodies/article32508101.ece. Accessed 13 Apr 2021.

17. Ghose A, Bhattacharya S, Karthikeyan AS, Kudale A, Monteiro JM, Joshi A, et al. Community prevalence of antibodies to SARS$\mathrm{CoV}-2$ and correlates of protective immunity in five localities in an Indian metropolitan city. medRxiv [Preprint]. 2020. https://doi. org/10.1101/2020.11.17.20228155.

18. Bhattacharyya R, Bhaduri R, Kundu R, Salvatore M, Mukherjee B. Reconciling epidemiological models with misclassified casecounts for SARS-CoV-2 with seroprevalence surveys: a case study in Delhi, India. medRxiv [Preprint]. 2020. https://doi.org/10.1101/ 2020.07.31.20166249.

19. Malani A, Shah D, Kang G, Lobo GN, Shastri J, Mohanan M, et al. Seroprevalence of SARS-CoV-2 in slums versus non-slums in Mumbai, India. Lancet Glob Health. 2021;9(2):e110-1.

20. National Commission on Population \& Ministry of Health and Family Welfare. Population projections of India and major states, 2011-2036 [Internet]. Nirman Bhawan New Delhi; 2019. https:// nhm.gov.in/New_Updates_2018/Report_Population_Projection_ 2019.pdf. Accessed 13 Apr 2021.

21. COVID19India. COVID-19 India [Internet]. 2020. https://www. covid19india.org/. Accessed 13 Apr 2021.

22. Mishra A. Covid-19 in UP: What August added-6 out of 10 infections, half of total deaths. The Indian Express [Internet]. 2020. https://indianexpress.com/article/cities/lucknow/covid-19up-august-6578963/. Accessed 13 Apr 2021.

23. Joseph JP. In comparative study of antibody sensitivity, 'Kavach' kit scores last. The wire [Internet]. 2020. https://science.thewire. in/the-sciences/antibody-test-kits-independent-verification-icmrzydus-kavach-sensitivity/. Accessed 13 Apr 2021.

24. Sapkal G, Shete-Aich A, Jain R, Yadav PD, Sarkale P, Lakra R, et al. Development of indigenous IgG ELISA for the detection of anti-SARS-CoV-2 IgG. Indian J Med Res. 2020;151(5):444-9.

25. Sempos CT, Tian L. Adjusting coronavirus prevalence estimates for laboratory test kit error. Am J Epidemiol. 2021;190(1):109-15.

26. StataCorp. Stata statistical software: release 16. 2019.

27. SeroTracker. Prevalence of antibodies against SARS-CoV-2 infection [Internet]. https://serotracker.com/en/Data. Accessed $13 \mathrm{Apr}$ 2021.

28. The Indian Express. First sero survey shows extensive spread of Covid-19: from $36.1 \%$ to $65.4 \%$ in selected areas sampled in Pune [Internet]. 2020. https://indianexpress.com/article/cities/pune/ first-sero-survey-shows-extensive-spread-of-covid-19-from-36-1to-65-4-in-selected-areas-sampled-in-pune-6558853/. Accessed 13 Apr 2021.

29. Financial Express. Coronavirus in Delhi: not everyone infected by COVID-19 has antibodies, July sero survey finds [Internet]. 2020. https://www.financialexpress.com/lifestyle/health/coronavirus-in-delhi-not-everyone-infected-by-covid-19-has-antibodiesjuly-sero-survey-finds/2071509/. Accessed 13 Apr 2021.

30. DownToEarth. COVID-19: Serosurvey estimated every fifth person in Chennai infected [Internet]. 2020. https://www.downt oearth.org.in/news/health/covid-19-serosurvey-estimated-everyfifth-person-in-chennai-infected-73170. Accessed 13 Apr 2021.

31. Frontline. COVID-19 in Haryana: study reveals 8 per cent seropositivity across 22 districts surveyed [Internet]. 2020. https:// frontline.thehindu.com/the-nation/haryana-survey-reveals-8-percent-seropositivity/article32648731.ece. Accessed 13 Apr 2021.

32. ThePrint. Indore sero survey finds $7.75 \%$ Covid exposure, 5 wards record exposure of over 20\% [Internet]. 2020. https://theprint.in/ health/indore-sero-survey-finds-7-75-covid-exposure-5-wardsrecord-exposure-of-over-20/491603/\%0D\%0A. Accessed 13 Apr 2021.

33. Saker L, Lee K, Cannito B, Gilmore A, Campbell-Lendrum D. Globalization and infectious diseases: a review of linkages. World Health Organisation. Geneva [Internet]. 2004. https://www.who. int/tdr/publications/documents/seb_topic3.pdf. Accessed $13 \mathrm{Apr}$ 2021. 